\title{
Rationale for a modified endotracheal tube for intubation using video laryngoscopy
}

\author{
Fu S. Xue, MD · Gui Z. Yang, MD • Gao P. Liu, MD
}

Received: 7 March 2016/Revised: 10 March 2016/Accepted: 19 April 2016/Published online: 6 May 2016

(c) Canadian Anesthesiologists' Society 2016

\section{To the Editor,}

We were greatly interested in the recent article by Emsley and Hung ${ }^{1}$ that described endotracheal tube (ETT) modifications for intubation using video laryngoscopy (VL). However, we believe that there are several aspects of this article that need clarification.

First, the authors reported that they successfully performed intubation in more than ten patients using a styletted, straight, Fastrach wire-reinforced silicone tube (Teleflex Medical, Markham, ON, Canada) with a C-MAC video laryngoscope (Karl Storz, Tuttlingen, Germany) without the ETT getting "hung up" on the anterior tracheal wall. We believe, however, that the problem of ETT being "hung up" on the anterior tracheal wall occurs more often during intubation using the more angulated VLs, such as GlideScope ${ }^{\circledR}$ (Verathon Medical, Bothell, WA, USA) and McGrath ${ }^{\circledR}$ (Aircraft Medical, Edinburgh, Scotland) VLs.

Compared with the angle of the blade at the base of the tongue characteristic of these VLs, the trachea descends from the larynx into the thorax at a posterior angle. ${ }^{2}$ The difference between these angles creates the potential problem of the ETT being "hung up" on the anterior tracheal wall. ${ }^{2}$ The more angulated VLs require use of a

This letter is accompanied by a reply. Please see Can J Anesth 2016; 63: this issue.

F. S. Xue, MD ( $\varangle)$ · G. Z. Yang, MD · G. P. Liu, MD Department of Anesthesiology, Plastic Surgery Hospital, Chinese Academy of Medical Sciences and Peking Union Medical College, Beijing, China

e-mail: xuefushan@aliyun.com; fushan.xue@gmail.com stylet, whereas the more conventional, Macintosh-type blade of the C-MAC VL allows successful intubation without using a stylet. ${ }^{3}$ Accordingly, as no stylet or preshaping of the ETT is required in most of these cases, difficulty passing the ETT because of impingement on the anterior tracheal wall does not occur as often with the CMAC VL. ${ }^{4}$ Thus, the authors' use of the C-MAC VL to validate the hypothesis whether a pre-curved styletted ETT can avoid the ETT from being "hung up" during intubation with VL may be misleading.

Second, to show the degree to which the standard ETT with an anterior angulation curves upward as a stylet is withdrawn, the authors used a malleable stylet to pre-form the distal part of the ETT into a $90^{\circ}$ "hockey stick" shape. In our experience, the greater the distal angle of the precurved styletted ETT, the more the distal part of the ETT curls upward during withdrawal of the stylet. When intubation is performed with the various angulated VLs in clinical practice, it is generally recommended that the ETT be pre-shaped with a malleable stylet to an angle similar to the blade curvature, such as an angle of $60^{\circ}$ for GlideScope ${ }^{\circledR}$ VL. ${ }^{4}$ Thus, their exaggerated distal ETT angle of $90^{\circ}$ may limit the clinical significance of their results.

Finally, the modifications they suggested for incorporation into a special VL ETT might already be present in a commercially available, specially designed ETT for the GlideScope ${ }^{\circledR}$ VL, such as the Parker FlexTip $^{\circledR}$ ETT (Parker Medical, Highlands Ranch, CO, USA). ${ }^{2}$ This ETT has a standard anterior curvature and a symmetrical tip with a ski-tip shape. When combined with the GlideRite ${ }^{\circledR}$ rigid stylet (Verathon Medical, Bothell, WA, USA), this ETT (compared with the standard ETT) can significantly improve intubation with the GlideScope ${ }^{\circledR}$ VL. ${ }^{5}$ 
Conflict of interest None of the authors received financial support, and there are no potential conflicts of interest for this work.

Editorial responsibility This submission was handled by Dr. Hilary P. Grocott, Editor-in-Chief, Canadian Journal of Anesthesia.

\section{References}

1. Emsley JG, Hung OR. A "VL tube" for endotracheal intubation using video laryngoscopy. Can J Anesth 2016; DOI:10.1007/ s12630-016-0595-0.

2. Levitan RM, Heitz JW, Sweeney M, Cooper RM. The complexities of tracheal intubation with direct laryngoscopy and alternative intubation devices. Ann Emerg Med 2011; 57: 240-7.
3. van Zundert A, Maassen R, Lee R, et al. A Macintosh laryngoscope blade for videolaryngoscopy reduces stylet use in patients with normal airways. Anesth Analg 2009; 109: 825-31.

4. Niforopoulou P, Pantazopoulos I, Demestiha T, Koudouna E, Xanthos $T$. Video-laryngoscopes in the adult airway management: a topical review of the literature. Acta Anaesthesiol Scand 2010; 54: 1050-61.

5. Radesic BP, Winkelman C, Einsporn R, Kless J. Ease of intubation with the Parker Flex-Tip or a standard Mallinckrodt endotracheal tube using a video laryngoscope (GlideScope). AANA J 2012; 80: 363-72. 